\title{
Postlaminectomy Bilateral Lumbar Intraspinal Synovial Cysts
}

\author{
Sung Ik Cho, Jung Hwan Lee, Chung Kee Chough \\ Department of Neurosurgery, Yeouido St. Mary's Hospital, The Catholic University of Korea School of Medicine, Seoul, Korea
}

Lumbar intraspinal synovial cysts are included in the difference diagnosis of lumbar radiculopathy. Developing imaging modalities has result in increased reporting about these lesions. However, the case of bilateral new lumbar intraspinal synovial cysts after laminectomy has been rarely reported. We report of a rare case with bilateral lumbar intraspinal synovial cysts after laminectomy, requiring surgical excision.

Key Words: Epidural space $\cdot$ Synovial cyst $\cdot$ Laminectomy $\cdot$ Lumbar vertebrae

\section{INTRODUCTION}

Lumbar intraspinal synovial cysts can be a cause of low back pain or lumbar radiculopathy ${ }^{12}$, but uncommon ${ }^{10)}$. The frequency of diagnosis may be on the rise due to the aging population and high diagnostic yield of magnetic resonance imaging (MRI) scans ${ }^{6}$. However, the case of bilateral new lumbar intraspinal synovial cysts after laminectomy is rarely reported. We described a case of postlaminectomy bilateral lumbar intraspinal synovial cysts caused recurrent radiculopathy.

\section{CASE REPORT}

A 62-year-old male with a claudication for several years visited St. Mary's Hospital. The leg pain was bilateral and aggravated recently, but muscle power and sensation were Intact. We diagnosed the spinal stenosis and grade I spondylolisthesis at the L4/5 level via the lumbar MRI (Fig. 1). Decompressive laminectomy at that level was performed. The patient was improved and discharged without complications. After 2 months, he revisited due to both legs pain for several days. On neurologic examination, he decreased muscle strength in plantar flexor muscles on both sides. On emergency lumbar MRI, 2 well-defined extradural cystic mass was identified (Fig. 2). The cysts were connected to facet joints and compressing

- Received: November 12, 2015 • Revised: June 29, 2016

- Accepted: July 12, 2016

Corresponding Author: Chung Kee Chough

Department of Neurosurgery, Yeouido St. Mary's Hospital, The Catholic University of Korea School of Medicine, 10 63(yuksam)-ro, Yeongdeungpo-gu, Seoul 07345, Korea

Tel: +82-2-3779-1187, Fax: +82-2-786-5809

E-mail: chough@catholic.ac.kr

$\otimes$ This is an open access article distributed under the terms of the Creative Commons Attribution Non-Commercial License (http://creativecommons.org/licenses/by-nc/4.0/) which permits unrestricted non-commercial use, distribution, and reproduction in any medium, provided the original work is properly cited. the thecal sac and both L5 nerve roots. Another cyst was identified above the left facet joint. We removed the cysts via the previous laminectomy site. The histopathologic examination revealed 0.5 - to $1-\mathrm{cm}$ cyst of fibrous connective tissue covered with synovial lining (Fig. 3). After revision surgery, the pain was relief and motor weakness was improved.
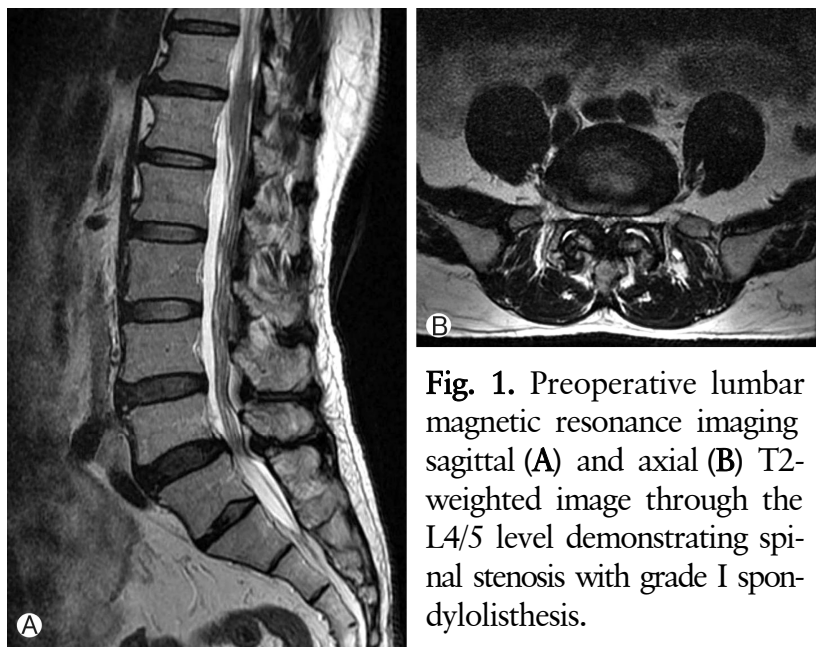

Fig. 1. Preoperative lumbar magnetic resonance imaging sagittal (A) and axial (B) T2weighted image through the L4/5 level demonstrating spinal stenosis with grade I spondylolisthesis.
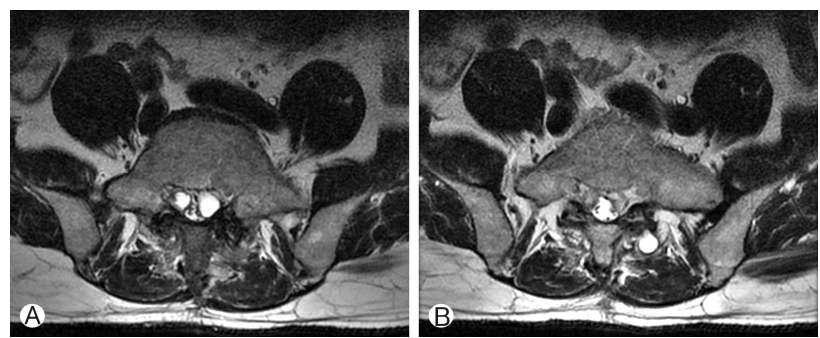

Fig. 2. Postlaminectomy lumbar magnetic resonance imaging axial T2-weighted image demonstrating bilateral lumbar intraspinal synovial cysts (A) and additional cyst above left facet joint (B). 


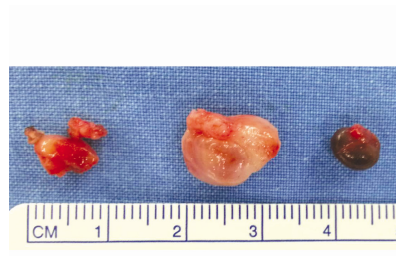

(A)

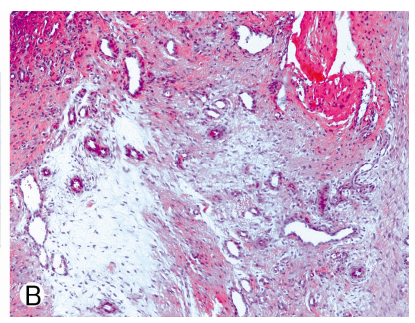

Fig. 3. (A) Removed lumbar intraspinal synovial cysts. Left mass was in right side epidural space and middle mass was in left side epidural space. Right mass was found during paraspinal dissection. (B) Pathologic findings show thick cystic wall with synovial lining cells $(\mathrm{H} \& \mathrm{E}, \times 100)$.

\section{DISCUSSION}

In 1885, Baker first described the formation of synovial cysts adjacent joints to a joint. Synovial cysts occur throughout the body, but spinal synovial cysts are uncommon ${ }^{11)}$. However, in the last decade, improving imaging modalities has resulted in increased reporting. Several authors reviewed spine MR images and computed tomographic images and reported that the incidence of synovial cyst was from $0.5 \%$ to $7.3 \% 0^{2,3,8)}$. On the other hands, postlaminectomy lumbar synovial cyst was rarely reported.

Walcott and Coumans ${ }^{11)}$ reported 10 cases of cyst formation after laminectomy for lumbar spinal stneosis. They could not estimate the incidence of postlaminectomy cyst formation because they did not systematically perform the MRI scan on all patients after surgery ${ }^{11)}$. They did not mention whether the cysts were unilateral or bilateral. And they performed reoperation for the cysts and confirmed pathologic results in 5 patients. On the other cases, they treated with the conservative management such as observation or epidural steroid injections and could not confirm whether the cysts were pathologically true synovial cysts ${ }^{11)}$. Howington et al. ${ }^{4)}$ also reported 5 patients with a prior surgery and subsequent development of intraspinal synovial cyst. All cysts were unilateral and removed surgically ${ }^{4}$. They reviewed the literature and found only 2 cases of bilateral intraspinal synovial cysts in $1999^{4)}$. And Lyon et al. ${ }^{9)}$ reported 194 patients with lumbar intraspinal synovial cysts who were surgically treated. Eleven percent of the patients had undergone previous lumbar spine surgery and eight of 194 patients were presented with bilateral synovial cysts ${ }^{9}$. However, they did not mention how many patients develop bilateral cysts after a prior lumbar spine surgery ${ }^{9}$.

Beside some debate remained, traumatic injury and segmental instability are the most often cited potential causative factors for the development of synovial cysts ${ }^{9}$. Recently, new theory about factors for development of intraspinal synovial cysts was suggested. Walcott and Coumans ${ }^{11)}$ proposed that ligament flavum excision may cause synovial cysts. Removing hypertrophic ligament exposes the medial aspect of the joint. This could cause the migration of synovium epidurally and the subsequent formation of the cyst ${ }^{11)}$.

The various treatment options for lumbar intraspinal synovial cysts have been discussed. Conservative treatment modalities include no treatment, bed rest, oral analgesics, physical therapy, orthopedic corsets, cyst aspiration and intra-articular injection and cyst puncture ${ }^{5}$. Some series have found that intra-articular injections provide acceptable long-term results, but these conservative treatments often show poor results, ${ }^{5,7}$. Surgical excision can achieve a complete resolution of symptoms with a very low incidence of complications and recurrence $^{7)}$. Bydon et al. ${ }^{1)}$ reviewed large literatures and reported that same-level cyst recurrence rate after surgical resection without fusion was $1.8 \%$. But, there was no recurrence of the cyst after surgical resection with fusion ${ }^{1)}$. They also reported that back and leg pain recurrence rate were $21.9 \%$ and $12.7 \%$, and $6.2 \%$ of patients required reoperation ${ }^{1)}$. The majority of reoperation required fusion for correction of spinal instability and mechanical back pain ${ }^{1)}$. They concluded that decompression and excision of lumbar intraspinal synovial cyst is safe and effect, but fusion of involved motion segment must be considered because of no recurrence of the cyst and back pain ${ }^{1)}$. Semiconstrained (or dynamic) spinal instrumentations such as transpedicular dynamic systems or interspinous spacers may be applied, but studies evaluating the follow-up of these techniques for treatment of intraspinal synovial cysts are still lacking in the literature ${ }^{7}$.

\section{CONCLUSION}

We reported a rare case of postlaminectomy bilateral lumbar intraspinal synovial cysts. In most cases, surgical excision is the treatment of choice for symptomatic lumbar intraspinal synovial cysts. However, the solid fusion after cyst excision must be considered if preoperative mechanical instability is identified or lumbar intraspinal synovial cyst recurs repeatedly.

\section{CONFLICT OF INTEREST}

No potential conflict of interest relevant to this article was reported.

\section{REFERENCES}

1. Bydon A, Xu R, Parker SL, McGirt MJ, Bydon M, Gokaslan ZL, et al: Recurrent back and leg pain and cyst reformation after surgical resection of spinal synovial cysts: systematic review of reported postoperative outcomes. Spine J 10:820-826, 2010

2. Doyle AJ, Merrilees M: Synovial cysts of the lumbar facet joints in a symptomatic population: prevalence on magnetic resonance imaging. Spine (Phila Pa 1976) 29:874-878, 2004

3. Eyster EF, Scott WR: Lumbar synovial cysts: report of eleven cases. Neurosurgery 24:112-115, 1989

4. Howington JU, Connolly ES, Voorhies RM: Intraspinal synovial 
cysts: 10-year experience at the Ochsner Clinic. J Neurosurg 91(2 Suppl):193-199, 1999

5. Khan AM, Girardi F: Spinal lumbar synovial cysts. Diagnosis and management challenge. Eur Spine J 15:1176-1182, 2006

6. Kouyialis AT, Boviatsis EJ, Korfias S, Sakas DE: Lumbar synovial cyst as a cause of low back pain and acute radiculopathy: a case report. South Med J 98:223-225, 2005

7. Landi A, Marotta N, Tarantino R, Ruggeri AG, Cappelletti M, Ramieri A, et al: Microsurgical excision without fusion as a safe option for resection of synovial cyst of the lumbar spine: longterm follow-up in mono-institutional experience. Neurosurg Rev 35:245-253, 2012

8. Lemish W, Apsimon T, Chakera T: Lumbar intraspinal synovial cysts. Recognition and CT diagnosis. Spine (Phila Pa 1976) 14:
1378-1383, 1989

9. Lyons MK, Atkinson JL, Wharen RE, Deen HG, Zimmerman RS, Lemens SM: Surgical evaluation and management of lumbar synovial cysts: the Mayo Clinic experience. J Neurosurg 93(1 Suppl):53-57, 2000

10. Park HS, Sim HB, Kwon SC, Park JB: Hemorrhagic lumbar synovial cyst. J Korean Neurosurg Soc 52:567-569, 2012

11. Walcott BP, Coumans JV: Postlaminectomy synovial cyst formation: a possible consequence of ligamentum flavum excision. J Clin Neurosci 19:252-254, 2012

12. Cho YD, Kim DH, Choi KH: Lumbar radiculopathy caused by intraspinal synovial cyst: a case report. Korean J Spine 5:36-38, 2008 